\title{
THE ASSESSMENT OF DIFFICULTY OF YACHT SAILING CLASSES AND STUDENTS' GLOBAL SELF- ESTEEM
}

Romanowska-Tołłoczko Anna, Piwowarczyk Piotr

University School of Physical Education in Wrocław

\begin{abstract}
Purpose: determination of relationship between the level of students' global self-esteem and their perception of the degree of difficulty sailing yacht classes. Material and methods: Study consisted of 178 students of University School of Physical Education in Wrocław. The study used two tools: Polish adaptation of SES M. Rosenberg Self-Esteem Scale and a questionnaire designed by the authors of the study. Results: men were characterized by a higher self-esteem than women. Distribution of the results obtained by women was closer to a normal distribution, but it was not completely compatible with it. The relationship was noted between the level of global self-esteem of the students and their perception of the degree of difficulty of the course. People with higher self-esteem assessed the knowledge and skills of sailing as easier. For people with lower levels of self-esteem sailing it was a more difficult. Conclusions: self-acceptance and selfesteem have a substantial impact on goal setting and the perception and taking various tasks. It is therefore important to help young people to build adequate self-esteem and positive self-image, because faith in its own strength and capabilities is a key element in achieving success in every area of life.
\end{abstract}

Keywords: students, self-esteem, sense of self-worth, yacht sailing, perception of classes difficulty.

\section{Introduction}

In the course of studies at the University School of Physical Education in Wroclaw students participate in summer camp, which is an integral part of the curriculum of universities in the fields of Physical Education and Tourism and Recreation. Subjects constituting the so-called "outdoor forms of physical activity", which include: canoeing, yachting, windsurfing, swimming in open water, games and recreation, and bicycling are realized during the camp [3].

The camp for full-time students lasts 10 days, during which yachting is conducted in two blocks of two and three hours. After the initial classes, students have the opportunity to choose the so called specialization of sailing and to hone their skills in this field for the next five days. However, for the purposes of this article, we deal only with people who undergo initial training. It includes a minimum basic knowledge of the construction of the yacht, sailing theory and safety rules. The first classes consist of a short presentation of the rules in sailing. The concept of wind and its types is explained Information about the construction of the yacht are presented in the process of preparing the boat to sail. These activities include: rigging the yacht and preparing the vessel for docks. The last part of the course is a cruise on the lake, during which students perform commands of instructor and work as a member of the crew maneuvering positions: in selecting, loosening, erecting and discharging of sails, at the helm, oars, on the moorings and the landing.

On the second day of classes, in the theoretical part, students learn about courses in relation to the wind, in which sailing boat can move, and basic information concerning the laws on the water. Then they have to independently prepare a boat to sail. After verifying the rigging, the crew together with an instructor comes to the lake. During the sailing students exchange the positions to perform activities such as working the sails and rudder. Tasks which they have to carry out are: keeping the course, sharpening and peeling from the wind, tacking and stern turning.

Sailing yacht belongs to difficult disciplines, requiring high knowledge and many skills and although the classes pass on only a small scope, it's for people who come into contact with this form of activity for the first time and for such a short time, it is a huge portion of the new material: vocabulary, theory and practice.

Sailing skills acquisition subjects to the same regularities that determine the process of learning and teaching each area. The effectiveness of this process consists of three basic elements: the properties of the learner, environmental conditions and course teaching situation and characteristics and competencies of the teachers [8.10].

In this study, we focused exclusively on the properties of the learner. The key features responsible for the acquisition of knowledge and skills include: intelligence, special abilities, interests, attitudes, motivation and self-esteem. These elements have been treated in a more selective and we focused exclusively on self-esteem. It may be understood in two ways, on the one hand as ambitions but also as an assessment of one's abilities within a certain range of activities and global activities $[16,17]$.

Global self-esteem is the belief in the self value, which can be high or low, and affect the assessment of the different life situations and setting and achieving the objectives in a positive or negative manner [12].

Self-image is one of the largest "force" of a personality, governing the behavior of man. Man behaves in life the in way one pictures oneself. If someone sees itself as a bold, brave, one acts boldly and courageously. If he or she considers oneself as a loser while, unfortunate, someone unworthy, one will behave so as to reaffirm their self-esteem $[11,18]$. People with high self-esteem have a positive attitude to the tasks undertaken because they have much faith in your success. Conversely, people with low self-esteem, for not believing in their own strengths, they recognize the many tasks too difficult. Fearing defeat, in advance doomed to failure and often do not even want to meet the demands for trial [13,14]. Empirical verification of the issues outlined above seems to be very interesting, and determining whether the correct discussed will also be visible in relation to the test group of students, the degree of difficulty involved in the assessment conducted by us sailing yacht classes. 


\section{Purpose}

The purpose of the study was to determine relationship between the level of students' global self-esteem and their perception of the degree of difficulty of sailing yacht classes.

We hypothesized that individuals with higher levels of self-esteem recognize the knowledge and skills of sailing for easier and faster to their learning, while students with lower self-esteem classes will constitute more difficulties.

\section{Material and methods of the research}

The study was conducted in 2014 in Olejnica at the Centre for Sports and Teaching, during summer camps for fulltime students. It was attended by 178 people, 72 women and 106 men.

The study used two tools: Polish adaptation of SES M. Rosenberg Self-Assessment Scale [7] and a questionnaire designed by the authors of the study. Self-assessment scale is composed of 10 claims, all are diagnostic. The result is the sum of points, which is a general indicator of the level of self-esteem. The range of possible points to obtain is between 10 to 40 points. Detailed interpretation of the received data is based on standards that can transform raw score on a scale sten.

Author's questionnaire contained 10 questions about attitudes of students to sailing, their assessment of the degree of difficulty of classes and self-esteem level of knowledge they have acquired skills and seamanship.

Students filled out questionnaires after the completion of the block of two classes. Statistical analysis was performed using Statistica 10.0.

\section{Analysis of the results}

\section{Attitude of students to sailing and assessment of difficulty's degree of classes}

The tested group of students consisted of people who came into contact with sailing for the first time in their life, so did not have any knowledge or experience in this field. Everyone began his contact with sailing with the same ceiling, which was the undoubted advantage of research.

The actions that a person undertakes for the first time are usually accompanied by emotions that are largely responsible for the attitude to the forms of activity. Depending on their type and strength, attitude can be positive or negative [6.20].

Sailing provides a lot of experiences that are somehow placed in the specifics of this discipline. Direct contact with nature, its beauty but also its dangers evokes different, often extreme emotions. At the outset, we asked students about their emotional state during yachting. Both women and men mostly felt pleasure (49\%) and interest $(36 \%), 10 \%$ of respondents said that swimming is boring for them, and for 5\% it was exciting.

Attitude is also linked to the interests and motivation [5.19]; that is why we asked the students if they would like to train sailing? More than three-quarters of men and women would like to acquire sailing skills, although their motivation was slightly different $-60 \%$ is guided by pleasure, and in $18 \%$ of the students dominate theme pragmatic. Other people $(6 \%)$ stated that they did not like sailing or it does nothing useful for them $(16 \%)$

Further issues related to theoretical knowledge transferred in the classroom and practical skills in demonstration. Students were asked to make a subjective assessment of the amount and degree of difficulty. Almost everyone agreed that the learning material was very extensive $(63 \%)$ and extensive $(32 \%)$, only a minority $(5 \%)$ found that it was not extensive enough.

In the learning process, the scope of material is an important factor in its assimilation, but for the efficiency of acquiring knowledge and skills more important is the subjective perception degree of difficulty.

Theoretical knowledge, in the opinion of women, for the $25 \%$ was easy, for $64 \%$ of medium difficulty and for $11 \%$ it was difficult. Rating of men was similar - $19 \%$ considered it to be easy, $59 \%$ for medium difficult and $22 \%$ as difficult.

The perception of the degree of difficulty of practical classes a bit different. Practical skills proved to be more difficult to control for women than for men, which was confirmed in their assessment. sailing

The level of students' self-esteem and their perception of the degree of difficulty of knowledge and skills of

Using the standards for students, global self-esteem of subjects was determined. Men were characterized by a higher self-esteem than women and this difference is statistically significant $(p<0,05)$. Distribution of the results obtained by women was closer to a normal distribution, but it was not completely compatible with it. Among women, a group of people with low self-esteem is much more numerous than the group with high self-esteem. While in men the size of groups from each level of self-esteem was similar, but among people with low self-esteem was until $1 / 3$ of the students (table 1). 
Table 1

Global self-esteem of the students

\begin{tabular}{|c|c|c|c|c|c|}
\hline \multirow{2}{*}{ Sex } & \multicolumn{3}{|c|}{ Self-esteem level } & \multirow{2}{*}{$\begin{array}{c}\text { Arithmetic } \\
\text { average }\end{array}$} & $\begin{array}{c}\text { Standard } \\
\text { deviation }\end{array}$ \\
\cline { 2 - 5 } & $\begin{array}{c}\text { LOW } \\
\%\end{array}$ & $\begin{array}{c}\text { AVARAGE } \\
\%\end{array}$ & $\begin{array}{c}\text { HIGH } \\
\%\end{array}$ & \\
\hline $\begin{array}{c}\text { Women } \\
\mathrm{n}=72\end{array}$ & 34,7 & 42,0 & 23,6 & 28,91 & 3,85 \\
\hline $\begin{array}{c}\text { Men } \\
\mathrm{n}=106\end{array}$ & 31,1 & 33,1 & 35,8 & 30,43 & 4,29 \\
\hline
\end{tabular}

The relationship was noted between the level of global self-esteem of the students and their perception of the degree of difficulty of the course. People with higher self-esteem assessed the knowledge and skills of sailing as easier. For people with lower levels of self-esteem sailing it was a more difficult (table 2 and 3 ). This regularity was observed in men and women, with the men's group differences in the mean result of self-esteem they were higher and statistically significant $(\mathrm{p}<0,05)$.

Table 2.

Perception of the level of difficulty of theoretical knowledge and the average of self-esteem

\begin{tabular}{|c|c|c|c|c|}
\hline Sex & $\%$ & $\begin{array}{c}\text { Difficulty level of } \\
\text { theoretical knowledge }\end{array}$ & Average self-esteem & Standard deviation \\
\hline \multirow{4}{*}{$\begin{array}{c}\text { Women } \\
\mathrm{n}=72\end{array}$} & 25,2 & Easy & 29,65 & 3,12 \\
\cline { 2 - 5 } & 63,8 & Moderately difficult & 27,66 & 4,01 \\
\hline \multirow{3}{*}{$\begin{array}{c}\text { Men } \\
\mathrm{n}=106\end{array}$} & 11,0 & Difficult & 27,50 & 3,74 \\
\cline { 2 - 5 } & 19,0 & Easy & 30,95 & 4,62 \\
\cline { 2 - 5 } & 21,6 & Moderately difficult & 30,44 & 4,16 \\
\hline
\end{tabular}

Perception of the level of difficulty of practical activities and the average of self-esteem

Table 3.

\begin{tabular}{|c|c|c|c|c|}
\hline Sex & \% & $\begin{array}{c}\text { Difficulty level of practical } \\
\text { activities }\end{array}$ & Average self-esteem & Standard deviation \\
\hline \multirow{4}{*}{$\begin{array}{c}\text { Women } \\
\mathrm{n}=72\end{array}$} & 2,7 & Easy & 29,25 & 1,41 \\
\cline { 2 - 5 } & 50,0 & Moderately difficult & 29,00 & 3,96 \\
\hline \multirow{3}{*}{$\begin{array}{c}\text { Men } \\
\mathrm{n}=106\end{array}$} & 47,3 & Difficult & 28,55 & 3,87 \\
\cline { 2 - 5 } & 17,0 & Easy & 32,33 & 4.05 \\
\cline { 2 - 5 } & 44,4 & Moderately difficult & 30,63 & 3,78 \\
\hline
\end{tabular}

\section{Discussion}

The results are a confirmation of the results obtained by other researchers, who defined the relationship between self-esteem and functioning of people in various areas of life. Research in this field of studies show that people with high self-esteem perceive themselves as more gifted, intelligent, popular, attractive, despite the fact that objectively do not differ in this respect from others. Such an assessment of self results in greater drive for success, and forms belief in achieving success as more realistic. If success indeed happens, then they assign it to their abilities, that, in turn, causes the integration of further positive information to the image of oneself and motivation to achieve further emotional gratification [1]. Individuals with low self-esteem are uncertain picture of me. They approach the task so as to avoid failures, which they consider very likely. When you actually meet them failing, they consider that failures are due to their personal lack of ability than external circumstances. Uncertainty self-image and a tendency to protect I mean that is unlikely to believe in the possibility of achieving success, despite the fact that their desire [2].

Significant differences between individuals with high and low self-esteem are also noticeable in the levels of endurance and activity. High self-esteem has an impact on making more different activities and more persistent pursuit 
of the goal. It is closely related with the conviction of self-efficacy and internal placement of control. People with high self-esteem are committed to the objectives related to achievements and are willing to take risks, while low self-esteem primarily orients human behavior to avoid failures and preference for safe situation [9].

\section{Conclusion}

Analysis of the results confirmed the hypothesis, put forward by us, that people with higher levels of self-esteem recognize sailing skills and knowledge as easier and learn faster, while students with lower self-esteem, these activities account for a bigger difficulty.

Self-acceptance and self-esteem have a substantial impact on goal setting, on perception and taking of various tasks [4]. It is therefore important to help young people to build adequate self-esteem and positive self-image, because faith in its own strength and capabilities is a key element in achieving success in every area of life [15].

Participation in the classes of sailing is an important contribution to the study of one's own personality and the opportunity to disclose existing potentials and abilities. Sailing is a challenging area of activity, and mastery of skills associated with it, gives you a great sense of satisfaction and success. Both these elements constitute an important factor in the formation of human self-esteem.

\section{Declaration of Conflicting Interests} this article.

The authors declared no potential conflicts of interest with respect to the research, authorship, and publication of

\section{References}

1 Baumeister RF, Campbell JD, Kreuger JI, Vohs KD. Does high self-esteem cause better performance, interpersonal success, happiness, or healthier lifestyles? Psychological Science in the Public Interest 2003;4(1):1-44.

2 Blaine B, Cocker J. Self-esteem and self-serving biases In reactions to positive and negative events. An integrating review. In: R.F. Baumeister (ed.), Self-esteem. The puzzle of low self-regard. New York; 1993. p. 5585.

3 Błacha R, Bigiel W, Wiesner W. (ed) Summer camps, Wrocław; 2011.

4 Branden N. The Six Pillars of Self-Esteem, Łódź; 2009.

5 Dryden G, Vos J. Revolution in studying, Warsaw; 2003.

6 Dubowik E. Regulatory processes. Emotions, In: E.Dubowik, R.Kościelak, H.Kulas, A.Tomczak-Witych, Selected psychology issues, Gdańsk; 2002. p. 49-96.

7 Dzwonkowska I, Lachowicz-Tabaczek K, Laguna M. Self-esteem and its measurement. Polish adaptation of M.Rosenberg's SES Scale. Textbook, Warsaw; 2008.

$8 \quad$ Fontana D. Psychology for teachers, Poznań; 1998.

9 Heimpel SA, Elliot AJ, Wood JV. Basic personality dispositions self-esteem, and personal goals: An approachavoidance analysis. Journal of Personality 2006;74:1293 -1319.

10 Kruszewski K. (ed) The art of teaching. Teacher's tasks, Warsaw; 2002.

11 Kulas H. Youth's self-esteem, Warsaw; 1986.

12 Niebrzydowski L, About self-knowledge and self-esteem, Warsaw; 1976.

13 Niebrzydowski L. The psychology of human's needs, aspirations and possibilities, Łódź 1999.

14 Niebrzydowski L. Educational psychology. Self-consciousness, activity, interpersonal relations, Warsaw; 1989.

15 Wegscheider-Crouse S. Sense of self-worth, Gdańsk, 2007.

16 Włodarski Z. Psychological features of learnig and teachig process, Warsaw; 1987.

17 Włodarski Z. (ed), Psychology of studying, Warsaw; 1998.

18 Siek S. Autopsychoterapia, Warsaw; 1985

19 Strelau J, Jurkowski A, Putkiewicz Z. The basics of psychology for teachers, Warsaw; 1997.

20 Zimbardo PhG. Psychology and Life, Warsaw; 1999.

Information about the authors:
Romanowska-Tolloczko Anna: http://orcid.org/000-0003-2236-
7519; anna.romanowska-tolloczko@awf.wroc.pl; University
School of Physical Education in Wroclaw Paderewskiego 35,
$51-612$ Wroclaw, Poland.
Piwowarczyk Piotr: http://orcid.org/0000-0003-2932-8328;
Piotr.Piwowarczyk@awf.wroc.pl; University School of Physical
Education in Wroclaw; Paderewskiego 35, 51-612 Wroclaw,
Poland.
Cite this article as: Romanowska-Tołłoczko Anna,
Piwowarczyk Piotr. The assessment of difficulty of yacht
sailing classes and students' global self-esteem. Physical




\section{education \\ of students \\ 2015;3:79-83.}

http://dx.doi.org/10.15561/20755279.2015.0310

The electronic version of this article is the complete one and can be found online at: http://www.sportpedu.org.ua/html/arhive-e.html

This is an Open Access article distributed under the terms of the Creative Commons Attribution License, which permits unrestricted use, distribution, and reproduction in any medium, provided the original work is properly cited (http://creativecommons.org/licenses/by/3.0/deed.en).

Received: 19.06 .2015

Accepted: 29.06.2015; Published: 30.06.2015 